\title{
ESTUDIOS DE NEGROS EN EL LITORAL PACIFICO COLOMBIANO
}

\section{FASE I}

GÜELMAMBI: FORMAS ECONOMICAS Y ORGANIZACION SOCIAL

\author{
Por: NINA S. FRIEDEMANN
}

ASPECTOS SOCIALES DE LA COMUNIDAD EN UN AREA RURAL DE BARBACOAS (NARIÑO)

Por: JORGE MORALES GOMEZ 


\title{
GÜELMAMBI: FORMAS ECONOMICAS Y ORGANIZACION SOCIAL
}

\author{
Por: NINA S. FRIEDEMANN
}

\section{I}

\section{INTRODUCCION}

En Colombia la escasez de estudios antropológicos entre negros es aguda y cuando se habla de las necesidades de la investigación antropológica en el país los grupos negroides no se mencionan con la importancia que deberían tener, aunque se sabe que en la composición de la población y en la cultura colombiana no solo los grupos indígenas y los blancos han participado dinámicamente. Como en el resto del Nuevo Mundo la esclavitud negra fue un hecho con proyecciones sociales, culturales y étnicas y en la actualidad los elementos negroides aparecen en sectores industriales, en zonas urbanas marginadas o en grupos rurales en sitios que albergan recursos naturales de importancia vital para la economía nacional.

Este proyecto de investigación corresponde al interés que tiene el Instituto Colombiano de Antropología y dos de sus antrópologos Nina S. Friedemann y Jorge Morales Gómez de realizar estudios sistemáticos entre grupos negroides del territorio colombiano. El proyecto en cuestión fue sometido por los citados antropólogos para la aprobación de la Dirección del Instituto en marzo de 1968. Más tarde cuando se tuvieron los datos sobre el reconocimiento físico del terreno y se habían localizado los grupos focales de la primera parte de la investigación, se propuso a la Dirección del Departamento de Antropología de la Universidad Nacional de Colombia la posibilidad de que dos estudiantes colaboraran como asistentes. Así el grupo de trabajo quedó integrado por dos investigadores principales y dos asistentes *, que se trasladaron al terreno en enero de 1969.

" Tito Zacipa y Jaime Atencio. 


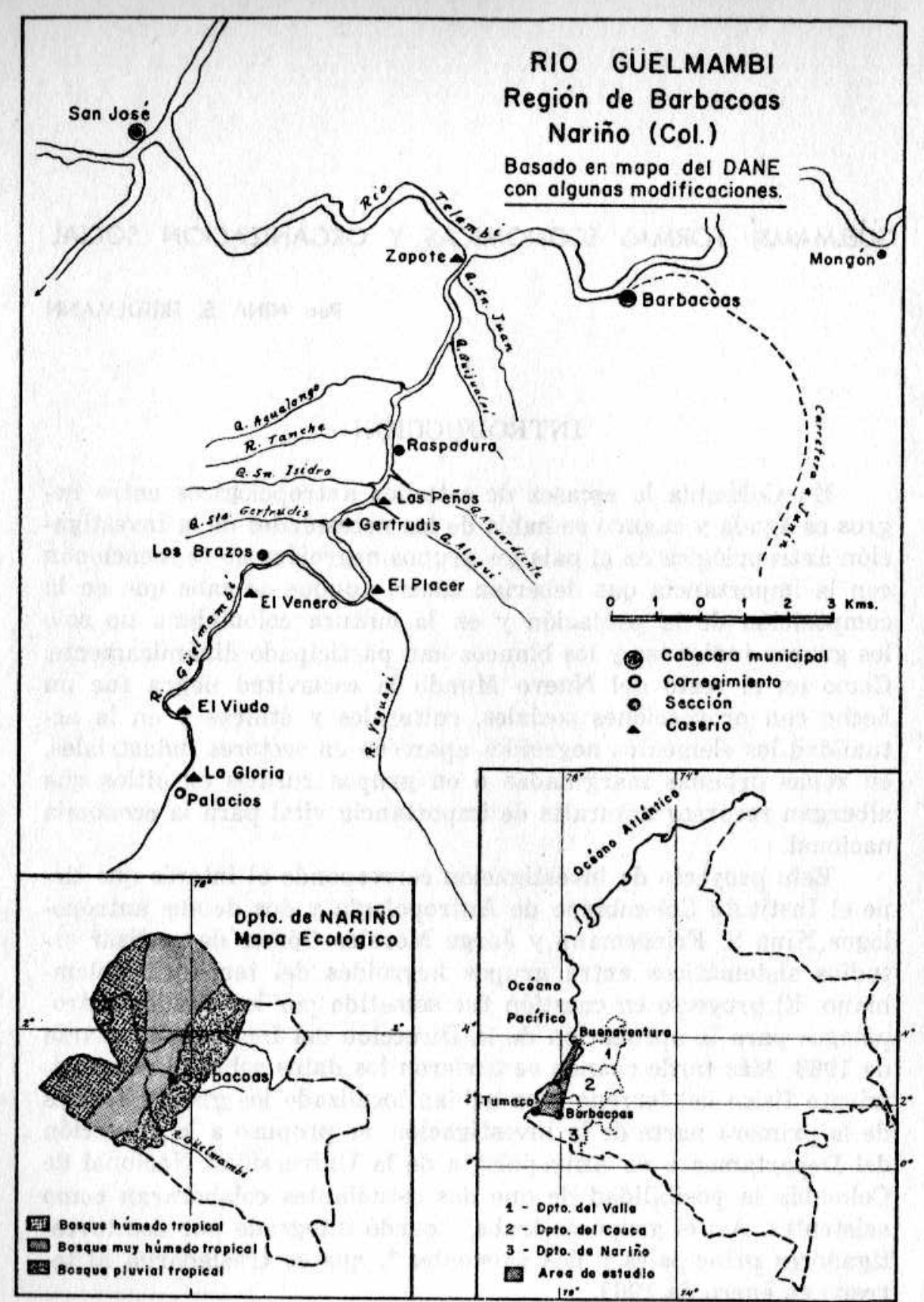

El proyecto general contempla el estudio de las formas de vida de los grupos negroides que habitan las dos áreas culturales (Price, 1954) del Litoral Pacífico Colombiano, a través de cuyo estudio se intenta a) reunir elementos válidos para definir las bases sobre las que debe apoyarse la variación cultural que confirme la delimitación tentativa de tales áreas y b) la investigación de las formas económicas, sociales y religiosas tendiente a delinear niveles de integración socio-cultural en cuanto a participación de los grupos en las formas de cultura de la nación.

La región geográfica donde se desarrolla el estudio yace sobre una parte de la franja tropical húmeda que se extiende a lo large del Océano Pacífico y que en el sur del territorio colombiano penetra hasta las estribaciones occidentales de la cordillera de Los Andes. Esta región conocida como Las Tierras Bajas del Pacífico alberga una mayor proporción de población negra que la convierte en una de las principales áreas negroides de América Latina, señalada asímismo como una de las menos conocidas en el ámbito científico (West, 1957). Más precisamente, el área actual de estudios está localizada entre los meridianos 78 y 79 al Oeste de Greenwich y las paralelas 1 y 4 al Norte del Ecuador, en una zona aproximadamente triangular delimitada por los focos urbanos de Buenaventura, Tumaco y Barbacoas.

El presente informe se refiere al trabajo de campo cumplido en la región económica de Barbacoas (Chaves, 1959) entre grupos de mineros independientes, que viven sobre el río Güelmambí y que políticamente hacen parte de la municipalidad de Barbacoas. La vida entre estas gentes es primitiva. Los sistemas de explotación minera heredados de los indígenas, así como sus cultivos elementales y el aprovechamiento del bosque maderable para sus canoas, vivienda y demás, tienen una tecnología rudimentaria que reclama el uso intenso y permanente de la energía humana, desde muy temprana edad. La alimentación es pobre, el dinero proveniente del oro de sus minas es escaso. Las condiciones de salud son precarias, los cabellos rojizos de los niños indican desnutrición, sus estómagos voluminosos acusan parasitismo. Los jóvenes que han ido a la escuela escasamente balbucean tratando de leer. Los sacerdotes católicos viajan a los caseríos desde Barbacoas solamente para las fiestas anuales de los santos patronos o en caso de epidemias y a solicitud del caserío, para hacer rogativas de salud. El resto del año las gentes celebran sus velorios, entierran a sus muertos con pasiones y chigualos (Whitten, 1967), pasean a los santos 
por el río, de poblado en poblado y se regocijan los sábados ya sea alrededor de la Virgen de Atocha $\mathrm{u}$ otro santo (Friedemann, en prensa) o en bailes al son de guitarras.

El objeto de este informe es el siguiente:

1) Mostrar brevemente el estado de progreso del proyecto de estudios en el Litoral Pacífico.

2) Registrar algunos datos escuetos obtenidos en el horizonte económico de un grupo de gentes que viven sobre el río Güelmambí en la región de Barbacoas.

3) Dar cuenta de los niveles de vida en que subsisten los habitantes de una de las zonas que conforman la región de Barbacoas, dentro de la que aparecen como un grupo sin mayores vinculaciones con la sociedad mayor.

4) Señalar la importancia que tiene el grupo de Los Brazos para la investigación antropológica, ya que se anticipan considerables cambios socio-culturales entre las gentes del río Güelmambí, a causa de los trabajos de explotación minera mecanizada que a través de adjudicaciones gubernamentales se harán allí próximamente.

La región de Barbacoas la encontramos mencionada en literatura de viajes (Triana, 1907), tratada en estudios de geografía humana (West, 1952, 1957) o en estudios socio-económicos generales del Departamento de Nariño (Rodríguez Guerrero, 1961, Chaves, 1959) ; sin embargo, no hemos localizado trabajos analíticos sobre las formas económicas y la organización social de los grupos negroides que viven a lo largo de los ríos en estos bosques tropicales.

\section{MATERIAL Y METODOS}

La selección del caserío Los Brazos se logró previo examen de informes y datos provenientes de sondeos exploratorios en la región de Barbacoas durante abril y agosto de 1968, que señalaron la minería como ocupación básica de los habitantes de un segmento del río Güelmambí en el bosque muy húmedo tropical. Los Brazos constituyó la unidad principal de estudio y observación, pero los caseríos y gentes de Las Peñas, Gertrudis, El Venero y Palacios también se visitaron. Los investigadores se ubicaron en Los Brazos en casas de sus habitantes y se movilizaron con ellos a los sitios de trabajo, lugares de reunión social y religiosa y estuvieron en la parte urbana del Municipio de Barbacoas, centro de mercadeo de la región a donde algunas gentes de Los Brazos acuden el día de la feria.

La estructuración del plan de trabajo en el campo se elaboró asignando el horizonte económico y el social separadamente a cada uno de los dos investigadores principales, dentro de una rigurosa correspondencia de objetivos. En la órbita económica se utilizaron bibliografía y los datos de los sondeos exploratorios, se adaptaron algunas líneas del modelo de investigación seguido en Tiv (Bohannan y Bohannan, 1968), todo lo cual se cotejó en una guía direccional de acuerdo con renglones del Manual Técnico IX de la Unión Panamericana (Murdock, 1963). En el terreno se trabajó con técnicas de observación y entrevista. Se recogieron biografías y comenzaron a estructurarse cuestionarios sobre actitudes. En las reuniones periódicas de control y evaluación del progreso del trabajo se modificaron algunos renglones direccionales, de acuerdo con las necesidades del terreno.

\section{I I}

LOS DATOS

\section{a) El sitio.}

El Municipio de Barbacoas, al que jurisdiccionalmente pertenece el río Güelmambí, tiene 17.836 habitantes, de los cuales 13.825 son rurales y hace parte del área cuyas densidades de población han sido calculadas entre 13 y 15 personas por kilómetro cuadrado (West, 1957). Los Brazos es un caserío del río Güelmambí, localizado a $1^{\circ} 37^{\prime}$ de latitud Norte y $78^{\circ} 14^{\prime}$ de longitud Oeste sobre una zona con una formación vegetal de bosque tropical muy húmedo, a una altura de 100 metros sobre el nivel del mar, con leves ondulaciones sobre el terreno, temperatura media de $28^{\circ}$, humedad entre 80 y $95 \%$ y una alta precipitación propia de la llanura del Pacífico, cuyo promedio anual de lluvias llega a los $8.000 \mathrm{~mm}$.

El caserío se levanta sobre una franja pedregosa, residuo de antiguas explotaciones mineras conocidas con el nombre de San Antonio, en poblamiento longitudinal con una extensión de 900 metros y tiene veinticinco casas, una escuela y una iglesia. Cada casa se yergue mirando hacia el río, separada de las demás por un espacio igualmente pedregoso al que existe entre el frente de la 
casa y el borde del banco del río que se desliza hasta las mismas aguas y donde crecen arbustos, algunos frutales y plantas ornamentales. La exuberancia del bosque llega hasta el pie de cada casa y se confunde con los rudimentarios jardines de frutales y hierbas medicinales que las gentes mantienen en los costados y detrás de las viviendas. En el caserío hay tres trapiches de madera, dos hornos, dos ranchos en donde se elabora la panela y una forja para reparar herramientas.

\section{b) Comunicaciones}

El río es la única vía de comunicación que los caseríos del Güelmambí tienen con Barbacoas y los poblados en la margen opuesta y la canoa es su elemento de transporte, pero algunos caserios sobre la misma margen del río se comunican por senderos rústicos. Aunque el radio de movilización del nativo en relación rústicos. Aunque el radio de movilización del nativo en relación con centros urbanos alcanza solamente hasta Barbacoas y se calcula en cuatro horas por canoa desde Los Brazos, vale la pena mencionar la pobreza de comunicaciones que existe entre Barbacoas y el resto del Departamento de Nariño. De Barbacoas sale un solo camino que empalma en el caserío Junín con la carretera que comunica Pasto con Tumaco. Ese camino con una extensión de 57 kilómetros no puede recorrerse en menos de cuatro horas en automotor debido al estado de abandono en que se halla. Los lunes son los días en que puede entrarse a Barbacoas en los camiones y buses que llegan al mercado del martes y salen ese día por la tarde. Otros días el viajero se sujeta a la posibilidad de espacio en algún camión que llegue a sacar madera de los aserríos. El servicio aéreo a Pasto ha sido suspendido y los vuelos a Tumaco son esporádicos. Así, Barbacoas constituye un hueco al que se entra o se sale en condiciones casuales de transporte fortuito.

Al caserío Los Brazos no llegan periódicos, ni los nativos los adquieren cuando van a Barbacoas, a menos que sean ediciones viejas para forrar las paredes de las casas. Existen seis radios transistores y tres de ellos sintonizan exclusivamente estaciones de Ecuador.

\section{c) Las gentes}

Desde el siglo diecisiete el área de Barbacoas ha sido asiento de negros que fueron introducidos como esclavos para las minas de oro de la región, conforme atestiguan documentos fechados en 1684 que se refieren al trabajo de tales esclavos en las minas sobre los ríos Telembí y Güelmambí entre tros (West, 1957). En la actualidad los grupos de esta región continúan trabajando con las mismas técnicas aprendidas de los indígenas durante la colonia y más aún, dentro de su cultura material surge un apreciable número de elementos aborígenes.

La comunidad de Los Brazos aparece como resultado de migraciones negras en Barbacoas a raíz del movimiento de emancipación y las gentes en su mayoría se identifican alrededor de tres apellidos de origen español cuyos portadores fueron dueños de minas en dicha región. Asímismo, los habitantes relatan la formación de su poblado a partir de la llegada de tres individuos, hace más de noventa años, a la margen occidental del río Güelmambí donde hoy se alza el caserío y donde constituyeron tres familias. Esas familias hicieron cada una su corte minero y empezaron a desmontar bosque alrededor de esos cortes para hacer cultivos y complementar la dieta familiar. De esta manera hoy se encuentran tres troncos genealógicos cuyos descendientes han continuado penetrando en el bosque de acuerdo con sus normas propias de registro de tierras en las que hacen minería y cultivos, y apoyados en un título de propiedad minera.

El caserío tiene en la actualidad 180 habitantes y el grupo doméstico en cada vivienda aparece constituído por el padre, la madre y los hijos; en algunos casos viven allí mismo nietos provenientes de uniones premaritales de los hijos mayores o de uniones de las hijas con hombres que tienen una esposa reconocida por el grupo como "la propia mujer". En un análisis preliminar de la composición de la población se nota una proporción de adultos entre los 18 y los 25 años emigrando a Cali, la costa nariñense o el Putumayo. No se registra inmigración hacia el caserío. Los datos de la investigación indican una natalidad alta y una mortalidad del 50\% en el grupo de edad 0-11 años.

Las causas más frecuentes de mortalidad entre recién nacidos son El $\mathrm{Mal}$, cuyos síntomas corresponden a tétano; entre niños mayores las enfermedades intestinales y de las vías respiratorias. Estos datos fueron confirmados por el hospital en Barbacoas, que informó cómo las gentes de los ríos acuden solamente en casos de extrema gravedad y que en raras ocasiones los parientes les permiten morir allí.

A la escuela asiste un promedio de 30 niños. La asistencia es irregular. La maestra enseña cursos correspondientes a dos años 
de primaria. Los recursos de la oficina de educación en Barbacoas son tan exiguos que en este semestre no pudo suministrar tiza y la maestra está enseñando sin utilizar el tablero.

\section{d) La vivienda}

En Los Brazos todas las casas son de madera, paradas sobre pilotes del mismo material con una altura entre $1.50 \mathrm{~m}$. y $2.00 \mathrm{~m}$., con techos de hojas de palma a excepción de cuatro casas que tienen lámina de zinc, cuyos jefes de familia trabajan asalariados en una firma minera extranjera. Su estructura y distribución siguen unas líneas generales que permiten utilizar el espacio entre el piso pedregoso y la habitación propiamente dicha para guardar las canoas, almacenar leña y guarecer los animales domésticos en sus corrales. Tres de las casas tienen un cuarto armado en el nivel bajo, que usan como tienda o taller. La estructura de "encima" tiene un cuarto principal con altar para los santos, una ventana o balcón sobre el río y es el sitio de reunión durante velorios, chigualos o bailes; el cuarto de dormir, una cocina con fogón alto y una azotea con rejilla de guadua donde se lavan los utensilios de cocina y se cuidan plantas medicinales en tarros. Alrededor de las divisiones de los cuartos hay plataformas de madera que sirven de bancos y otras más anchas sobre las que se duerme. Son frecuentes los asientos y banquetas así como alacenas en las cocinas, y algunas camas y mesas.

El agua del río sirve para todos los menesteres domésticos. La basura se recoge en artesas de madera que vacían en el río Este y el monte son los sitios donde se cumple la excreción. Para el alumbrado tienen mechas de algodón con petróleo en empaques de hojalata, cuya luz los protege durante el sueño de los ataques de murciélagos que allí merodean continuamente.

\section{e) La tierra}

\section{Propiedad y derechos}

La propiedad de la tierra y los derechos a trabajar en las minas de invierno (Restrepo, 1888) están condicionados a la pertenencia por descendencia o parentesco afín a uno de los tres troncos genealógicos de Los Brazos. Registrar un terreno para el uso y la herencia significa limpiar y delimitar un área de tierra dentro de la propiedad del tronco genealógico del individuo interesado y comunicar el hecho al grupo. Este registro puede hacerse siempre y cuando el área no haya sido desmontada y no tenga señales de haber sido sembrada o bien el dueño anterior no desee usar más el terreno y conceda el dominio al nuevo aspirante. En Los Brazos las gentes tienen sus tierras en el monte y en las vegas del río Güelmambí que en frente del caserío en la margen opuesta permite el cultivo del arroz, la caña de azúcar y el plátano. Así, cada vivienda tiene un área en las vegas al otro lado del río, importante porque es un sitio muy cercano en donde se corta plátano o caña en cualquier momento, ya que las chagras en el monte a menudo están a una hora de camino.

La herencia de la tierra y de los derechos a trabajar en las minas en lo que concierne a la familia, se estructura a medida que los hijos crecen y están en capacidad de trabajar y contribuír a la economía familiar. Un padre o una madre por ejemplo, entregan a un hijo un pedazo de tierra para que lo limpie y lo siembre, pero parte del producto debe contribuír a la dieta familiar. Sin embargo, cuando el joven se casa el terreno queda de su propiedad y cesa la obligación de participar al mantenimiento de la casa de sus padres. Así, al final del ciclo vital el individuo ha distribuído entre sus hijos su propiedad de tierras y su derecho a trabajar en las minas.

Este proceso de registro, herencia de terrenos y derechos a trabajar en las minas que el grupo practica, tiene lugar sobre una extensión que de acuerdo con la Ley 292 de 1875 les fue adjudicada a perpetuidad a los primeros descendientes de los negros que allí llegaron a raíz de la emancipación, según consta en el instrumento público número 1201 de mayo 11, 1899, que se halla protocolizado en la Notaría de Barbacoas, con fecha diciembre 28, 1962. No obstante, a causa de que los descendientes no han seguido de cerca el proceso jurídico de la propiedad del suelo y del subsuelo, su dominio en la actualidad se limita al subsuelo. Así la legislación nacional que regula la propiedad del suelo considera a estas gentes colonos en tierras baldías a pesar de que estas descendencias según el análisis genealógico aparecen enclavadas en ese lugar desde hace 106 años.

Una consideración somera de lo anterior ofrece la evidencia de una estructura formal de propiedad y herencia propias del grupo, vigente durante cerca de un siglo y sin ningún significado frente al régimen de propiedad territorial de Colombia.

\section{f) Tecnología}

El medio ambiente se explota principalmente a base de la fuerza física individual o socialmente reunida. Las herramientas son escasas y en gran parte hechas de madera. Para la minería usan la barra de hierro, y el almocafre, combinación de hoja metálica 
y mango de madera; el resto de los implementos son de madera o de calabazo. En la chagra se trabaja con el machete para sembrar y limpiar, el hacha para tumbar árboles, el palito plantador, el palo de guadua para proteger semillas y el garabato de madera para bajar los frutos. En la fabricación de implementos de madera y hechura de canoas se observa el mayor número de herramientas como azuelas planas y gubias, garlopas, cepillos planos y lomeros que en Los Brazos son propiedad de los hombres considerados como expertos en estas labores.

La técnica más frecuente de la minería es aquella por medio de la cual el oro se consigue después de desbaratar la peña que contiene conglomerados de piedra, barro y arcilla y de lavar y movilizar manualmente todo este material. En la chagra la téc nica de la "tumba" por medio de la cual se derriban los árboles que sirven de lecho para el riego del maíz o de abono para las cepas de plátano requiere hombres fuertes y diestros en el manejo del hacha y del machete. Las mujeres, los niños y los hombres bogan en canoas ayudados de palancas y canaletes y transportan cargas por entre la selva anudando bandas vegetales a sus cabezas y colgando de éstas canastos, hechos por ellos mismos. Los trapiches manuales los mueven hombres y mujeres; las canoas se hacen en los bosques y las arrastran hasta el caserío. La fuerza, la salud y la resistencia física son necesarias en estos bosques y asímismo su ausencia o disminución acarrean sanción social como en el caso de dos individuos que han sido excluídos de todas las actividades y permanecen recluídos en sus casas aunque sus enfermedades podrían permitirles movilización en el poblado.

\section{g) Trabajo}

\section{Minería}

Los habitantes de Los Brazos dedican la mayor parte de su tiempo a la minería independiente, a excepción de cuatro hombres que trabajan en la firma extranjera que tiene su campamento principal en la sección Mongón sobre el río Telembí. Llamamos minería independiente a la explotación del oro que hace un individuo o un grupo por su propio riesgo y cuenta en oposición al trabajo asalariado de minería mecanizada que varios hombres hacen en la firma citada. El mazamorreo o extracción del oro de las quebradas por medio del lavado de las arenas, es trabajo que en el caserío solamente lo practican unas mujeres viejas y las viudas.
La minería independiente se hace principalmente en minas de invierno, clasificadas como de tonga (Restrepo, 1888) y con dos sistemas de explotación diferenciados, conocidos como el comedero y la compañía.

El comedero es un corte pequeño, situado en terrenos del tronco genealógico con el que se identifique el grupo familiar asentado en cada vivienda, que lo explota para el mantenimiento de la familia. Las normas de división de labor y participación de parte de la producción, así como las de autoridad, reflejan las pautas observadas en la explotación de compañía.

La compañía es un corte minero grande sobre un área de terreno extensa, que requiere la colaboración de un número apreciable de hombres y mujeres que trabajan allí si pertenecen al tronco genealógico con derechos sobre tales terrenos. Esta forma de explotación se hace en ciclos de varios meses, cada uno de los cuales se llama "un picado", dentro de los cuales se cumplen etapas de trabajo y normas sobre tiempo del año en que se cambia el oro por dinero, participación de la producción, división del trabajo por sexo y edad y estructuras de decisión y autoridad, a las que este informe no va a referirse.

La familia trabaja tres días en su comedero y asiste a la compañía los tres días restantes; el domingo se descansa. De esta manera el comedero provee para el gasto diario y el producto del trabajo en la compañía asegura la compra de artículos y ropas para las fiestas religiosas anuales, la Semana Santa y la Navidad, ocasiones que coinciden con la terminación de cada uno de los ciclos de explotación del sistema compañía.

Al trabajo en la compañía asisten gentes que viven en los caseríos de Gertrudis, El Venero, Las Peñas y Palacios; en este último sitio se registró la existencia de cortes-compañía cuya explotación se cumple con las mismas pautas de cooperación condicionadas por la descendencia genealógica. Además, en uno de los cortes-comedero de Los Brazos se encontraron trabajadores con vivienda en Las Peñas, pero hijos de la cabeza de familia que controla ese comedero.

\section{La chagra}

En los períodos del año cuando las lluvias escasean y la minería es menos intensa lo que sucede alrededor de enero y febrero, julio y agosto, se cuida la chagra, se remozan los cultivos de plátano, se riega arroz y maíz y se labran las canoas. Estas activida- 
des requieren la cooperación de varios individuos, cuya ayuda es reciprocada con el mismo tipo de trabajo en un lapso de tiempo cercano o como en el caso de la elaboración de la caña, con unidades de panela que se distribuyen de acuerdo con el número de participantes, la propiedad de la caña y los implementos de trabajo. Estos grupos de trabajo se estructuran en los lugares de reunión social y con ocasión de velorios o bailes en la comunidad o en otros caseríos vecinos.

\section{Caza y pesca}

Son actividades complementarias que operan como paliativos durante los períodos "secos" del año cuando el dinero es poco y la escasez de alimentos causa angustia. El producto efectivo de las trampas para conejos o ratones o de los "galandros", que son cuerdas con varios anzuelos es incierto. Más bien la pesca en las quebradas por medio de la raíz del barbasco es efectiva, pero acuden a ella solo en estado de profunda necesidad alimenticia. El trabajo y la distribución del producto de la caza y de la pesca sigue las mismas normas de cooperación y reciprocidad como en la chagra.

\section{i) Intercambio}

\section{En Los Brazos}

En el caserío hay dos tiendas en donde se venden artículos como cebolla, harina, avena, manteca, carne o pescado salado y aguardiente, cerveza, gaseosas y tabaco. Allí también se compra el polvo de oro a los mineros que emplean el dinero correspondiente en la adquisición de los víveres que ofrece la tienda. Se observaron transacciones de compra de un grano de oro por valor de Ps. 3.15, peso que resulta de balancear el oro con un grano de maíz (10 granos $=$ un adarme $; 16$ adarmes $=1$ onza) y transacciones de venta de tres cucharadas de avena por treinta centavos y diecisiete gramos de manteca por veinte centavos, los que corresponden a una de las treinta partes en que se divide el bloque de una libra para su venta. Estos ejemplos ilustran la forma del intercambio oro-dinero-víveres y el volumen en que se lleva a cabo y puede dar una idea de la escasa disponibilidad de efectivo que la producción minera permite a sus trabajadores. Las tiendas conceden a sus clientes entre los que se cuentan gentes que viven en Las Peñas, Gertrudis y El Venero y que trabajan en los cortes-compañías de Los Brazos, un crédito que debe cancelarse antes de que el dueño viaje a Barbacoas a hacer las compras, lo que sucede cada dos semanas; tales créditos no exceden los Ps. 30.00 * por vivienda.

El producto de las chagras se consume dentro de la familia y en el caso de que hubiere excedentes estos se distribuyen en el caserío entre los allegados con vínculos de más amistad o parentesco que en ese día o tiempo no tengan en su chagra tal producto. En la misma forma los favorecidos reciprocan sus productos a los primeros.

Otras formas de intercambio interno se presentan en términos de servicios reciprocados y repartición de productos entre los grupos de trabajo ya sean familiares o comunales. En el ámbito familiar, por ejemplo y con ocasión del nacimiento de un hijo las hermanas de la nueva madre se encargan de lavarle las ropas durante los días en que madre e hijo están recluídos en su casa y en la misma forma esta mujer prestará el servicio a sus hermanas cuandoquiera que ellas tengan sus nuevos hijos. En el monte el trabajo que implica la hechura de una canoa requiere la fuerza de varios hombres a quienes el dueño de la canoa suministra comida y aguardiente; cada uno de los participantes, sin embargo, tiene a su vez el derecho de llamar en su ayuda al dueño de la canoa para que colabore en la construcción de la propia. Ahora bien, en el caso de la cacería cuando un hombre logra cazar una presa con la escopeta ya sea de su vecino o de su suegro, a éste le participa proporcionalmente por un sistema que se conoce como de las tres una, que establece el derecho del dueño de la herramienta sobre una de las tres partes en que para el efecto se divide el producto.

\section{Con otros caserios}

Las transacciones de compra y venta que Los Brazos tiene con otros caseríos se reducen al crédito que las tiendas dan a algunos de los trabajadores en los cortes-compañías de Los Brazos y a la compra y venta de aguardiente que ocasionalmente se cambia por su valor equivalente en gallinas y huevos. Estas transacciones sin embargo, llegan en área geográfica solamente hasta El Venero en la parte alta del río Güelmambí y en la parte baja hasta Las Peñas.

\section{En Barbacoas}

Las transacciones de Los Brazos que es el centro del mercado de la región a donde confluyen víveres de la comarca de Ipia"US\$ $1=$ Ps. 16.50. 
les como la carne de res, quesos, legumbres o bien de la propia costa nariñense como el pescado salado y una variedad de plátano muy apetecido, se limitan con exclusividad al cambio del oro por dinero para la compra quincenal de las provisiones que surten cada tienda durante dos semanas cada vez y esta venta y compra la hacen en su mayoría los dueños de las tiendas. El volumen mensual de compras de cada tienda en Barbacoas, oscila entre Ps. $1.200 \mathrm{y}$ Ps. 1.600, datos estos que fueron confrontados con el volumen de venta mensual de oro que uno de los dueños de tienda de Los Brazos hace regularmente al Banco de la República * y que alcanzó un total de 95.8 gramos por los que recibió Ps. 1.772.30. Esta suma corresponde a una fecha que se encuentra en un período lluvioso fuerte, la cual puede compararse con la correspondiente a un mes de los llamados "secos" que registra una venta de 42.6 gramos con un valor de Ps. 754.12, hecho en el mismo banco por el mismo individuo. Ocasionalmente al final de un ciclo de trabajo de cortecompañía, el viejo elegido por el grupo de trabajo acude a Barbacoas y cambia el oro por dinero que repartido individualmente entre los participantes del ciclo, se invierte en el mismo Barbacoas en ropa y comida que se acostumbra para las fiestas anuales y las celebraciones de Semana Santa y Navidad.

\section{IV}

\section{RESULTADOS PRELIMINARES}

Dentro del horizonte socio-económico, en el caserío Los Brazos sobre el río Güelmambí, los primeros ejercicios de análisis del material ofrecen los siguientes puntos:

1) El parentesco respalda una estructura formal de propiedad, herencia y derechos de trabajo propia del grupo, pero sin validez frente al régimen institucional de propiedad de la nación colombiana.

2) Las gentes viven dentro de una economía de subsistencia con pautas de cooperación y reciprocidad de carácter formal. Su participación en el mercado regional es restringida si se tiene en cuenta que los cultivos rudimentarios no presentan excedentes y el intercambio de pequeñas cantidades del producto minero logra artículos básicos de consumo que ellos no producen. En este intercambio el precio de venta del oro así como el de compra de provisiones se fijan exteriormente y fuera del control del grupo.

* Oficina de Compras de Oro en Barbacoas.

$68-$
3) La familia y la agrupación de trabajo minero son los grupos sociales a los que está más ligado el habitante del caserío. La labor en la mina comedero afirma la pertenencia del individuo a determinado núcleo familiar y doméstico y la participación en la mina de compañía expresa la descendencia de un tronco genealógico particular.

4) La tecnología tradicional rudimentaria se basa en el uso intenso de energía humana individual o socialmente reunida en el trabajo y transporte. La fuerza, capacidad de resistencia física y salud son altamente valoradas y lo contrario se sanciona con exclusión social del individuo.

5) No se aprecia una contribución significativa de las instituciones de la sociedad mayor en la vida de esta agrupación que aparece aislada del conjunto socio-cultural de la municipalidad.

Asímismo, en el proceso de este análisis preliminar aparece la problemática del marco tipológico conceptual dentro del cual ha de examinarse esta agrupación, que en primera instancia se localiza intermedia entre sociedades cuyas características las señalan tribales y las consideradas industriales. Tal segmento genéricamente denominado campesinos, en los últimos años ha sido punto de atención de un grupo apreciable de antropólogos interesados en estudios de gentes que habitan los llamados sectores rurales. En el panorama de América Latina particularmente, desde hace más de una década han estado apareciendo contribuciones que se esfuerzan por delinear elementos sobre los que se apoyen las tipologías que puedan servir de marcos de referencia al estudio de esos segmentos humanos intermedios, a tiempo que se ha sugerido intensificar la investigación antropológica entre grupos que ofrezcan materiales para el desarrollo de tipologías apropiadas (Wolf, 1955, 1966).

El grupo negroide que habita las riberas del Güelmambí localizado en el bosque tropical muy húmedo de tierras bajas del Pacífico surge entonces como una posibilidad en la participación del desarrollo de esas tipologías ya que sus características hasta el momento de este ejercicio analítico no han permitido su clara categorización, no obstante la amplia conceptualización (Firth, 1952) de que no solamente agricultores sino pescadores y artesanos rurales y entonces tal vez caucheros y mineros puedan incluírse dentro de una tipología de campesinado. Este enfoque y el concepto de culturas parciales campesinas (Wolf, 1955) en cuyo desarrollo el trayecto histórico correspondiente a la esclavitud negra se utilice en el examen de la supervivencia de relaciones propias del sistema socio- 
económico de explotación minera colonial como son las que modelan en la actualidad el trabajo en los cortes comedero o compañía, pueden presentar una variación al vasto marco de referencia genérico.

Ahora bien, si la distinción entre sociedades primitivas y campesinas yace en el carácter de las relaciones externas del grupo (Wolf, 1955), por ende lo significativo no es lo que el individuo o grupo produce -artículos agrícolas o polvo de oro- sino entre quiénes y cómo se dispone de ese producto (Foster, 1967). Si por otra parte el control de la tierra es cuestión que implica no solamente el suelo, sino el subsuelo en extensiones cuya superficie es tratada como tierra marginal por la sociedad mayor, entonces se anticipa un considerable campo de estudio y discusión entre estos grupos negros.

\section{R E F E R E N C I A S}

BohanNan, PaUl y LaUra, 1968. - Tiv Economy. Northwestern University Press. Evanston, Ill.

Chaves, Milcíades, 1959. - Nariño. Ministerio de Trabajo. División Técnica de la Seguridad Social Campesina. Bogotá.

Firth, RAYMond, 1952. - Elements of Social Organization. London, Watts.

FOSTER, GeorGe, 1967.-What is a peasant? Peasant Society. The Little, Brown \& Co. Boston.

Friedemann, Nina S. - En prensa. Contextos religiosos en un área negra de Barbacoas. "Revista Colombiana de Folclor". Vol. IV, No 10.

MURDock, GEORGE P. y otros, 1963. - Guia para la clasificación de los datos culturales. Unión Panamericana Secretaría General, OEA. Manuales Técnicos, IX. Washington.

Price, Thomas J., Jr., 1954. - Estado y necesidades actuales de las investigaciones afro-colombianas. Revista Colombiana de Antropología, Vol. II, pp. $11-36$.

RESTREPo, VICENTE, 1888. - Estudio sobre las minas de oro y plata de Colombia. Bogotá.

Rodríguez GUerroro, Ignacio, 1961. - Geografía Económica de Nariño. Pasto.

Triana, Miguel, 1907. - Por el Sur de Colombia. Excursión pintoresca y científica al Putumayo. Garnier Hermanos, París.

West, RoBert C., 1952. - Colonial Placer Mining in Colombia. Louisiana State University Press. Baton Rouge, La.

- 1957. The Pacific Lowlands of Colombia. Louisiana State University Press. Baton Rouge, La.

Whitten, Norman, 1967. Música y relaciones sociales en las tierras bajas colombianas y ecuatorianas del Pacífico: Un estudio de microevolución cultural. América Indígena XXVII, No 4, pp. $635-665$.

WoLF, ERIC, 1955. - Types of Latin American Peasantry: A preliminary discussion. American Anthropologist. Vol. 57, № 3, pp. 452-471.

- 1966. - Peasants. Prentice Hall, London.

Fotografías de N. S. Friedemann.

\section{ASPECTOS SOCIALES DE LA COMUNIDAD EN UN AREA RURAL DE BARBACOAS (NARIÑO)}

\author{
Por: JORGE MORALES GOMEZ
}

\section{INTRODUCCION}

El presente informe es un complemento al presentado por la antropóloga Nina S. Friedemann en las páginas anteriores sobre la zona minera del río Güelmambí, al occidente de Barbacoas, en el Departamento de Nariño. Mi interés específico de estudio en este proyecto es el funcionamiento de las relaciones sociales en la te proyecto es "Los Brazos" y los nexos de ésta con la sociedad mayor, para establecer al final de la investigación, el grado de integración social y política que tiene dicha localidad con el nivel nacional.

\section{PLAN DE ESTUDIO EN EL TERRENO}

El trabajo de investigación tiene por una parte un carácter etnográfico que corresponde a la recolección de los datos y su respectiva descripción, y por otra, un criterio etnológico que coincide con el análisis de las informaciones obtenidas y la formación de generalizaciones para el área minera de Barbacoas. El primer aspecto o sea la recolección de datos sobre las relaciones sociales en la comunidad siguió un plan que expuesto esquemáticamente es el siguiente :

I. Estructura física de la comunidad.

II. Status adscritos y adquiridos.

$$
\begin{aligned}
& \text { A. Funciones. } \\
& \text { B. Prestigio. }
\end{aligned}
$$

III. Actividades cohesivas.

IV. Actividades disgregantes.

V. Relaciones con la sociedad mayor. 


\section{METODOLOGIA}

El material logrado en el terreno ha sido orientado siguiendo de una manera reflexiva las clasificaciones culturales hechas por Murdock y colaboradores (1963), las investigaciones de Horowitz entre los negros de Martinica (1967) y el modelo teórico elaborado por Steward sobre Niveles de Integración Socio-cultural (1963).

En el campo se utilizaron dos técnicas básicas de investigación social:

1. La observación, tanto participante como no participante, y

2. Las entrevistas.

Para mi estudio, la observación fue muy importante; grupos de edad, trabajo cooperado, reciprocidad de servicios, repartición de las cosechas, explotación minera y sus relaciones sociales implicadas son algunos de los aspectos que por medio de la observación pudieron conocerse y fueron profundizados más con la técnica de las entrevistas. Estas se hicieron semiestructuradas y no estructuradas, según los informantes y el objeto averiguado.

Generalmente no se apreció tensión de los informantes por el hecho de que se tomaran notas mientras ellos hablaban. Tal actitud hace parte de la buena acogida que tuvimos en la comunidad los investigadores y los dos estudiantes de la Universidad Nacional, Jaime Atencio y Tito Zacipa. De este modo, no se presentaron mayores obstáculos para lograr la relación de confianza o rapport.

\section{MATERIAL ETNOGRAFICO}

No expongo el "corpus" total de los datos recogidos durante el mes de enero de 1969, debido a la calidad de informe preliminar de esta publicación y a la circunstancia de que la investigación aún está incompleta.

"Los Brazos" está ubicado en el curso medio del río Güelmambí; consta de 25 viviendas, una capilla, escuela y casa de habitación para la maestra. Las construcciones por su distribución conforman un típico caso de poblamiento lineal sobre la vega occidental del río.
Toda la estructura física del caserío se considera localmente como única, no se reconocen divisiones internas en sectores o delimitaciones funcionales. Existe sí una separación notoria entre la primera casa (bajando el río) y el resto de la localidad. Tal distancia es irregular, en relación a la que existe entre todas las otras viviendas, y en su recorrido aparece una cerca que interrumpe el camino principal que es paralelo al río.

Además de esta vía, existen comunicaciones terrestres que son ramales de aquéllas y conducen a los campos de cultivo y cortes mineros.

$\mathrm{La}$ comunidad tiene dos tiendas que se abren diariamente. En ellas se venden productos elaborados, traídos de Barbacoas como gaseosas, cerveza, queso, cigarrillos, tabaco en rama, dulces, pastillas analgésicas e hilos; sus dueños se constituyen en compradores locales de oro el cual van a venderlo después en Barbacoas.

\section{I}

La mujer desempeña una función socio-económica importante dentro del grupo. Al igual que el hombre, desde temprana edad ( 5 o 6 años) inicia su asistencia a los cortes mineros para conocer las técnicas asignadas a su sexo. Más tarde, hacia los 11 años, el proceso de socialización establece que la niña entre ya a trabajar formalmente en la explotación del oro y a participar en los sistemas de repartición del mineral, si está como trabajadora asalariada, posición que a tal edad ya puede adquirir. Ella se ocupa esencialmente en las "guascas", cadenas humanas que van retirando las piedras derribadas por los hombres, profundiza los canalones haciendo más fino el barro dentro del cual se encuentra el oro, y "playa" con las bateas para separar finalmente el metal de la "jagua". Son también las mujeres quienes guardan el oro hasta que se va a vender a Barbacoas.

$\mathrm{Al}$ elemento femenino se le otorga gran poder de decisión; ella es quien dirige la distribución de los ingresos familiares y en materia religiosa, su participación es muy necesaria; en los velorios a santos son las mujeres las cantadoras y quienes dan la pauta que han de seguir los músicos. Todo esto nos indica que el status social de la mujer es alto.

Al hombre se considera localmente como elemento trabajador y la cultura le ha asignado ciertas fases de laboreo en la minería, como "covar" que es oficio hecho sólo por los varones en las 
"compañías" y por ambos sexos en las minas de "comedero". También los hombres "jalan" y "chocan" en el canalón junto con las mujeres, transportan piedras pequeñas o "cascote" en "pondos" de madera. Ellos se dedican a la agricultura en cooperación con las mujeres, cazan, pescan con dinamita y con anzuelos y fabrican aguardiente y lo distribuyen a lo largo del río en diferentes caseríos. También la administración política local está en poder de los hombres, así como el cuidado del cementerio, la iglesia y la escuela.

Hacia los 11 años, al muchacho, al igual que a las niñas, se le dan cerdos para que críe y matas de plátano que debe cuidar, o tierra para cultivar. Los productos o dinero que obtenga de tales actividades son para los padres, pero cuando el muchacho se case, esos bienes pasan a ser propiedad suya. Así se va estructurando el sistema de pertenencia dentro de la unidad familiar. Hacia los 18 años, la capacidad de decisión del muchacho ha aumentado de manera que ya puede irse a trabajar a Tumaco, Cali, el río Mira o al Oriente en el campamento de la Texas Petroleum Campany en la localidad de Orito, que son los principales destinos en la migración de la población joven.

Los viejos son objeto de respeto y aprecio dentro de la comunidad. Su opinión es muy importante en deliberaciones de orden político, como son las gestiones para que a "Los Brazos" se le dé nuevamente la categoría de sede del corregimiento "Olaya Herrera". También se piensa que los viejos son los individuos de mayor experiencia en materia religiosa, relatos históricos, partos (comadronas), y generalmente la gente se dirige a ellos con el término "tío" (o tía) para expresar una relación social de respeto.

Entre las actitudes y elementos culturales que proporcionan prestigio a los individuos, se pueden anotar, omitiendo por ahora la significación de ellas: ser jornalero, saber leer, haber salido a ciudades (Cali, Tumaco), gastar aguardiente a los amigos, hacer fiestas, tener radio, pantalón de paño, zapatos, casa con techo de zinc, tienda y joyas.

\section{I I}

La cohesión de los miembros de la comunidad se establece principalmente en base al parentesco, las actividades económicas y las expresiones religiosas. El caserío de "Los Brazos" se originó a partir del asentamiento de tres troncos familiares dedicados al laboreo de las minas de oro. Hoy día, todas las personas de la localidad se consideran unidas por lazos de parentesco consaguíneo o afín, que tal como lo expone Nina S. Friedemann, constituyen un marco de referencia dentro del cual se estructuran la propiedad y la herencia. La naturaleza cohesiva del parentesco radica en que la gente reunida en torno a una categoría social que supone normas de mutua ayuda y excluye individuos vistos como "extraños". Tal tendencia integradora se expresa en testimonios como el siguiente: "A los del mismo caserío que somos todos enfamiliados se les presta cosas, se presta más a los del caserío que a los de otras partes". Evidentemente, se puede observar que el hecho de compartir un territorio común está intrínseco dentro de la condición social de "enfamiliados".

El compadrazgo o parentesco ritual refuerza las relaciones interpersonales de tipo diádico al crear nuevas expectativas de colaboración y protección que se tienen hacia los padrinos de los hijos. En varias ocasiones, tal circunstancia social asume un carácter asimétrico al escogerse como compadre a un individuo representante de la sociedad mayor.

Las actividades económicas que fomentan el "sprit de corps" dentro de la comunidad son ante todo los trabajos colectivos y la reciprocidad de servicios. Labrar una canoa, cortar trozas de madera y transportarlas a los aserríos de Barbacoas, las cosechas y la molienda de caña, son algunas de las circunstancias que demuestran la importancia del trabajo cooperado. Generalmente se espera que cuando alguien presta un servicio, más tarde va a tener la colaboración del beneficiado para cualquier trabajo que necesite varias personas. Esta red de reciprocidades aumenta las relaciones cara a cara entre la gente y funciona según ciertas pautas preferenciales de interacción que hacen que un individuo coopere más con algunos que con otros, dentro de un sistema de posibilidades además del parentesco.

Las gentes mantienen una intensa actividad religiosa que se manifiesta en el culto. Todas las casas tienen altares con imágenes de diversos santos haciendo énfasis en el Sagrado Corazón de Jesús, que es el patrono de la población, y en las distintas advocaciones de la Virgen María (Atocha, El Carmen, Perpetuo Socorro). Tal pauta de comportamiento hace parte de la expresión religiosa en el nivel familiar de integración socio-cultural. A nivel comunal, son los velorios, los chigualos, las procesiones a lo largo del río con un santo que va en peregrinación, y las fiestas patronales a las que asiste un sacerdote de Barbacoas, las ocasiones en las cuales se despliega mucha energía social expresada en contextos religiosos y económicos. Las relaciones interpersonales especialmen- 
te son activas en las tiendas que se abren y que durante las fiestas del Corazón de Jesús reúnen gentes de los caseríos vecinos que toman aguardiente y comida cocinada que para los visitantes se prepara en tales ocasiones.

Finalmente, la solidaridad se afianza por un complejo cultural de naturaleza política, originario de la sociedad mayor: todo el caserío tiene conciencia de que representa un núcleo liberal y por esa circunstancia particular que no se halla muy evidente en centros urbanos, el sentimiento de unión es mayor y especialmente en tiempo de elecciones.

I V

Frente a las actitudes socio-culturales que aumentan la solidaridad, aparecen otras que crean tensión y cierto grado de agresividad. Atrás se anotó que físicamente, dentro de la localidad había un distanciamiento entre la primera casa y la que seguía, considerado mayor en comparación con la pauta de colocación de las viviendas general a la comunidad. Además de presentarse la razón de que la dueña es enferma de pián y no puede trabajar sistemáticamente, lo cual la separa de una de las actividades más valoradas en la comunidad, ella es conocida localmente como "chismosa y le gusta alegar", motivo por el cual hay cierta resistencia a mantener activo contacto con ella y expresión de tal actitud es la negativa de que los niños de otras familias entren a su casa.

El chisme a la vez que es un medio de control social efectivo, fomenta la tensión dentro del grupo. Se considera que las mujeres tienen más capacidad para ejercer una acción crítica sobre la conducta de los demás que no es aceptada socialmente. Tales comentarios forman en ocasiones disgustos entre unidades familiares y parece que cuando el objeto de esas críticas son los jóvenes, los padres de éstos trasladan hacia ellos la ofensa verbal a sus hijos ampliándose así el radio de tensión entre las familias.

La poliginia se rechaza idealmente pero en la realidad se practica y aunque produce agresividad entre los esposos por una parte y las mujeres por otra, la comunidad la acepta en el sentido de que se permite a un hombre tener otra mujer además de la original (de matrimonio o extramaritalmente) siempre que la sostenga económicamente junto con los hijos que existan de tal unión. Lo que muestra la estructuración de las relaciones poligínicas es que tal situación está sujeta a pautas establecidas de carácter obligatorio, como la aludida responsabilidad por la mujer y los hijos. Asociada a esta práctica de la poliginia está la presencia de relaciones premaritales como fuente de tensión entre los miembros del caserío. Muchos jóvenes tienen experiencias sexuales antes de contraer matrimonio o de tener una compañera. Al saberse esta realidad, la comunidad hace un despliegue de energía social exteriorizado en las críticas a tal pareja y extendiéndose en muchas veces a la familia nuclear de los comprometidos en la relación.

El conflicto en algunos casos se origina por las relaciones existentes entre la comunidad y la sociedad mayor. El caserío de "Los Brazos" últimamente se ha visto frente a una fase de inestabilidad política, pues antes fue sede del corregimiento, la cual fue trasladada a "Palacios" y los habitantes de "Los Brazos" ven que su localidad ha decaído a la categoría de inspección de policía dependiente de "Palacios".

Por otra parte cuando llegan sacerdotes a la comunidad critican las prácticas poligínicas de los individuos y el consumo de aguardiente lo cual riñe con tales hábitos socialmente aprendidos por las personas.

Las relaciones de "Los Brazos" con la sociedad mayor o nacional se cumplen en Barbacoas para solucionar algunas de las necesidades que tienen los habitantes rurales. En la población nariñense, los individuos de la citada comunidad no participan dentro de una verdadera actividad de mercados, sino que solamente adoptan una posición receptiva o de consumo con los ingresos que les suministra la venta del oro. En este sentido, podemos decir que se hallan marginados de un sistema de mercados, causa de lo cual es la agricultura de subsistencia que no permite tener un excedente de producción destinado al mercado, sino al almacenamiento, para la selección de semillas.

El sistema de tenencia de la tierra como lo ha dicho antes Nina S. Friedemann, no está vigente dentro de los cánones legales de la Nación al respecto, sino que se estructura más en sistemas locales como el parentesco y la apropiación de campos abandonados por gentes de afuera en materia fiscal y agrícola. Los propietarios ausentistas no ejercen ningún control sobre estos colonizadores quienes tienen conciencia de que la apropiación es permitida por el gobierno y la han estructurado según criterios de herencia familiar. 
Los apoyos sociales o económicos que los mineros de "Los Brazos" contraen con gente de Barbacoas, se expresan principalmente en la relación del compadrazgo asimétrico, en préstamos in formales con personas conocidas y solamente se hacen créditos formalizados con letras, para la compra de radios.

Finalmente, en materia de integración sanitaria, educacional, de obras públicas y de comunicaciones, la situación actual es in cipiente y se manifiesta en la conciencia que los individuos tienen de que "el gobierno no nos ayuda".

Algunos puntos de análisis que hemos podido establecer en el curso de esta etapa de terreno, han sido:

I. Dentro de un marco teórico antropológico, los habitantes de "Los Brazos" no son considerados compesinos por varias razones:

$1^{\text {a }}$ No dependen básicamente de la actividad cultivadora de la tierra.

$2^{\mathrm{a}}$ No mantienen un fondo de renta constante ya que los mineros independientes no pagan impuestos y no hay un control sobre la tierra por personas de afuera.

$3^{a}$ No participan en sistemas mercantiles sobre la base del excedente de la producción.

II. "Los Brazos" constituye un grupo primario, ya que sus miembros mantienen relaciones cara a cara, reforzadas por la condición social del parentesco.

III. La circunstancia de vecinos parece ser la solución más frecuente ante las diversas posibilidades de cooperación, después del vínculo de parentesco.

IV. El prestigio parece ser el canal más importante de acercamienmiento a las normas de comportamiento y elementos de la sociedad mayor.

\section{RE F E R E N I A S}

Horowitz, Michael M., 1967. - Morne-Paysan. Peasant Village in Martinique. Holt, Rinehart and Winston, New York.

MURDock, G. P. et al., 1963. - Guía para la clasificación de los datos culturales. Unión Panamericana, Washington.

STEWARD, Julian, 1963. - Theory of Culture Change. University of Illinois Press. Urbana.

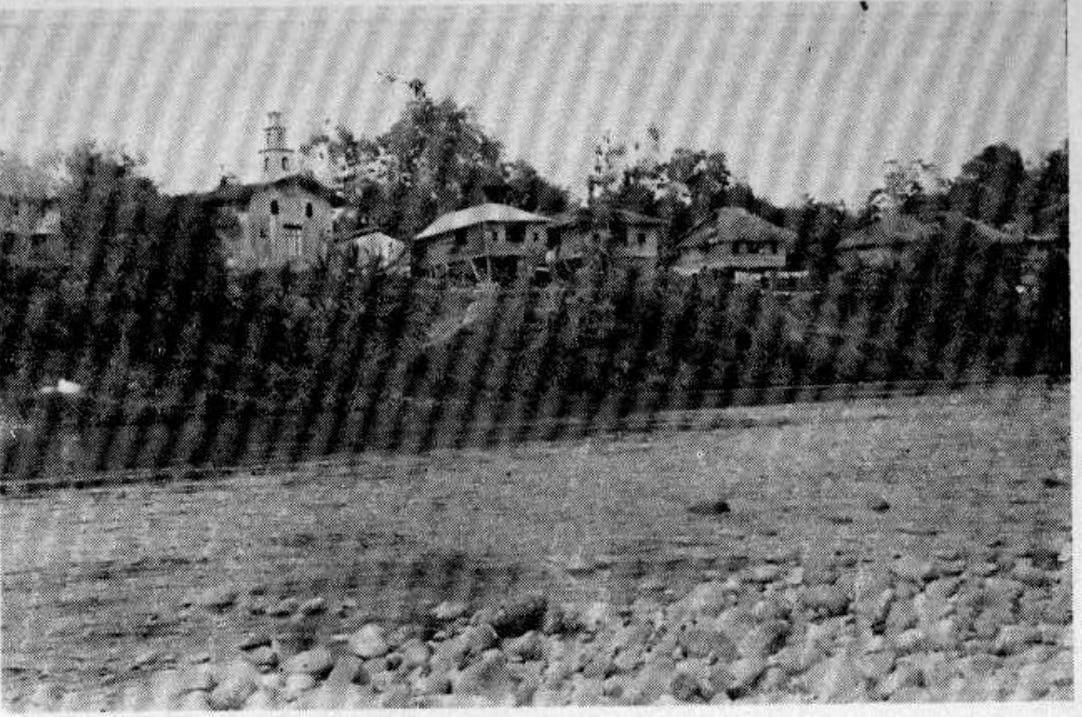

El caserio "Los Brazos" sobre el rio Güelmambi, Barbacoas (Nariño)

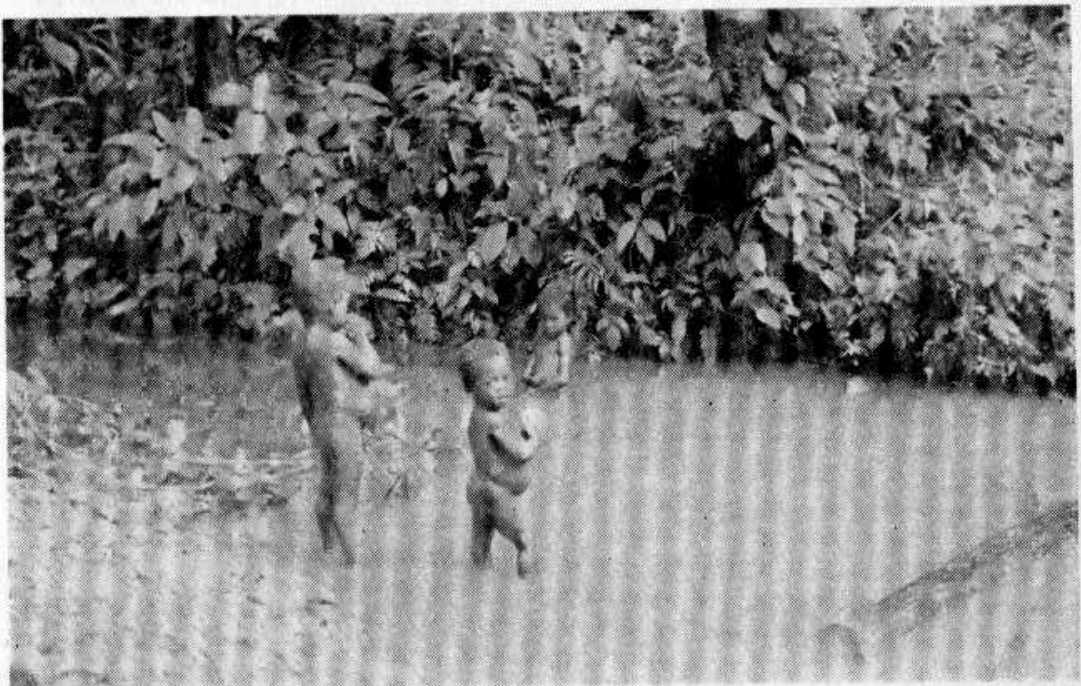

En el río Güelmambí.

Las condiciones de salud son precarias, los cabellos rojizos de los niños indican desnutrición, sus estómagos voluminosos acusan parasitismo. 


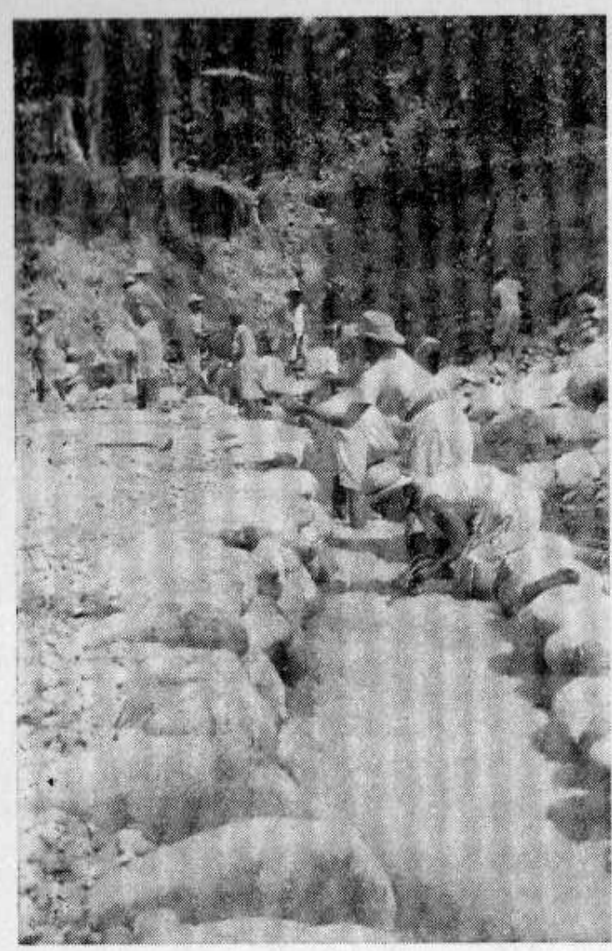

Mina de invierno "Naguare"

La fuerza física se reúne socialmente para explotar el oro.

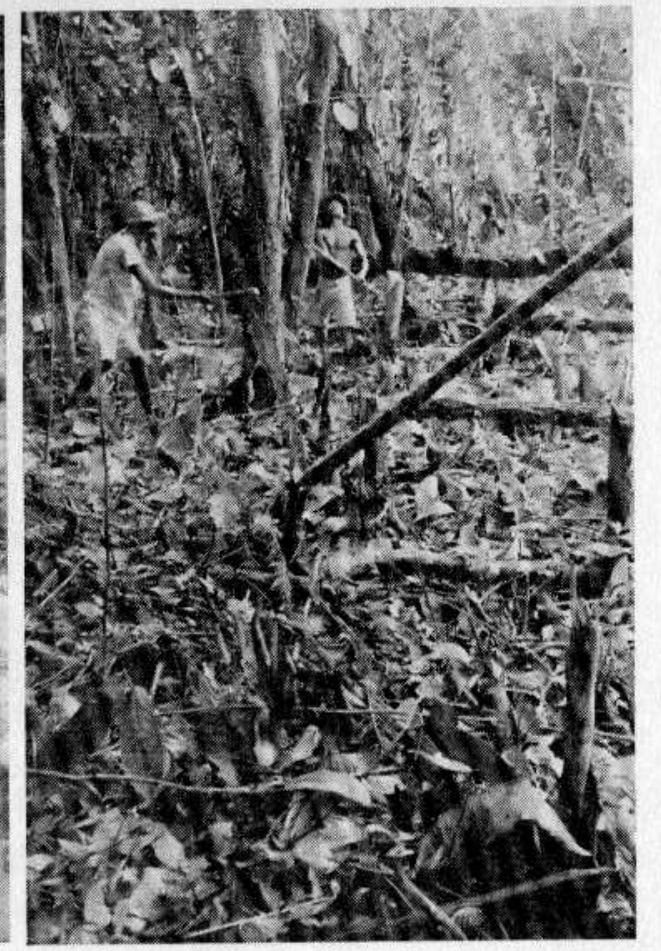

"La tumba" de árbolęs en el monte es labor importante para los cultivos rudimentarios de maiz.

Vestido usado por las

madres y mujeres

viejas mientras están en el caserío.
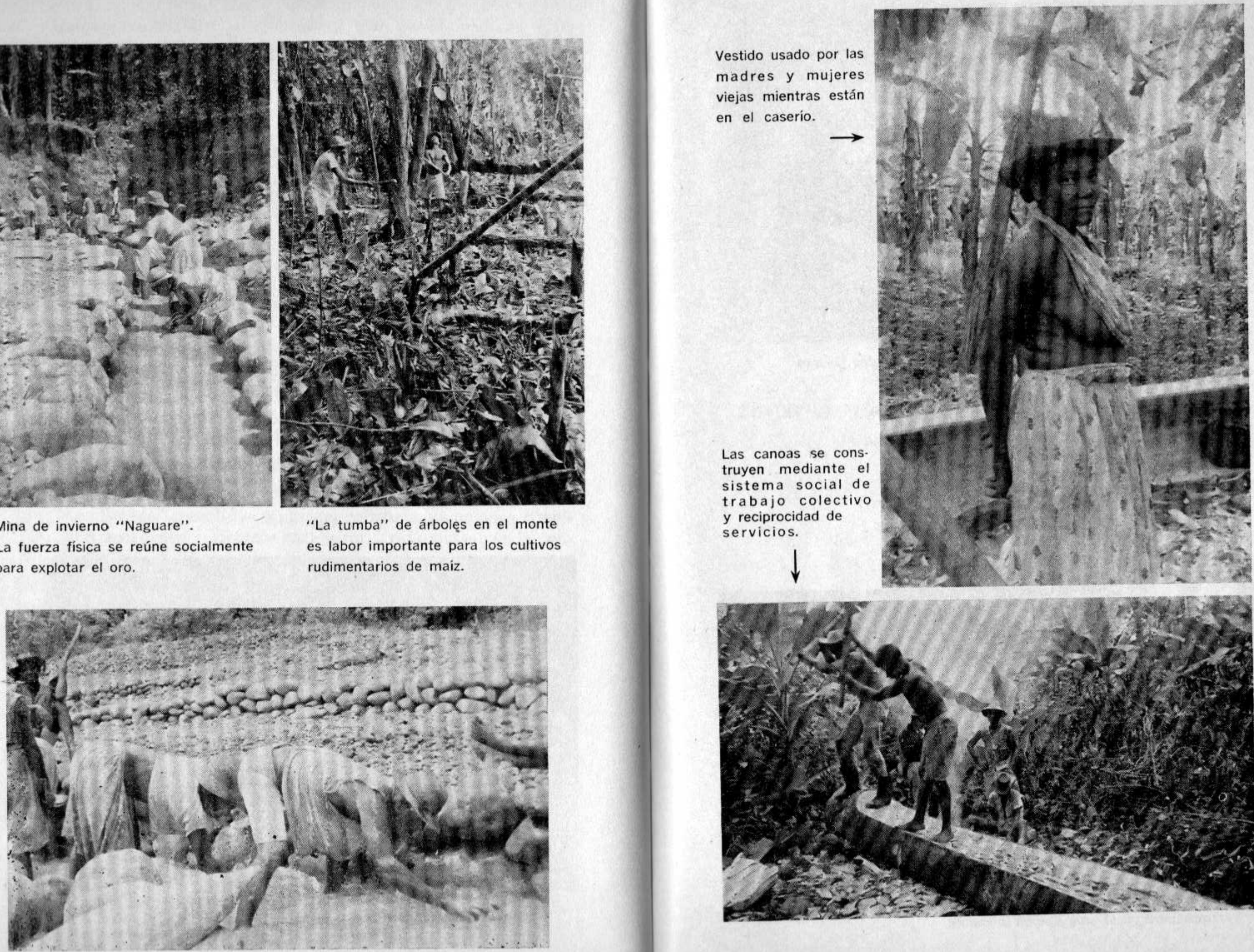

Las canoas se cons

truyen mediante

sistema social de

trabajo colectiv

y reciprocidad de

servicios.

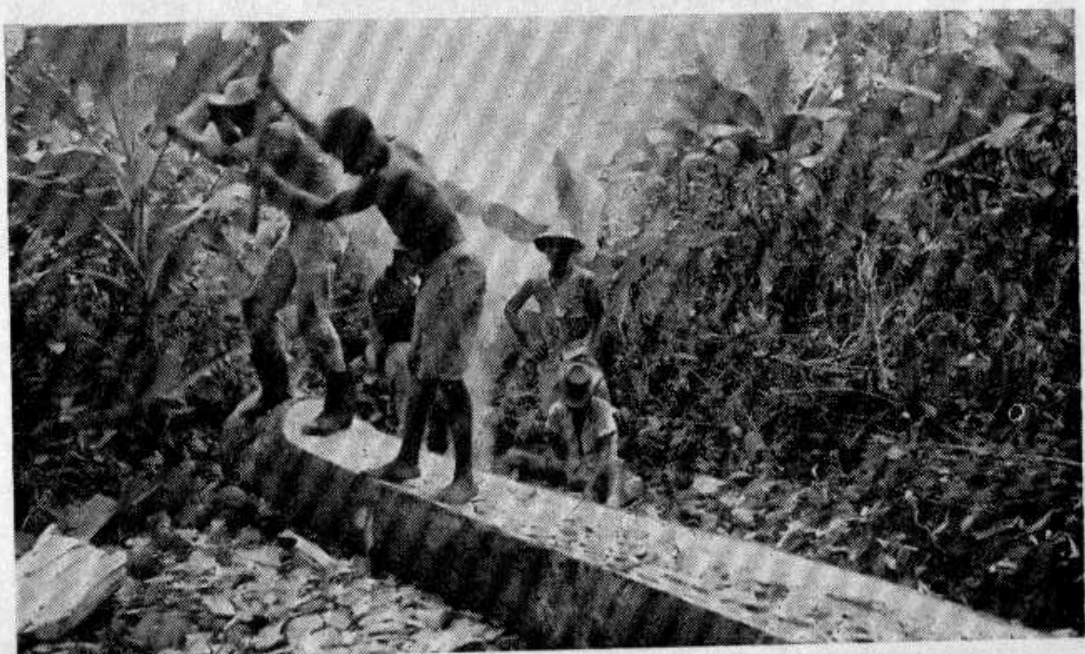




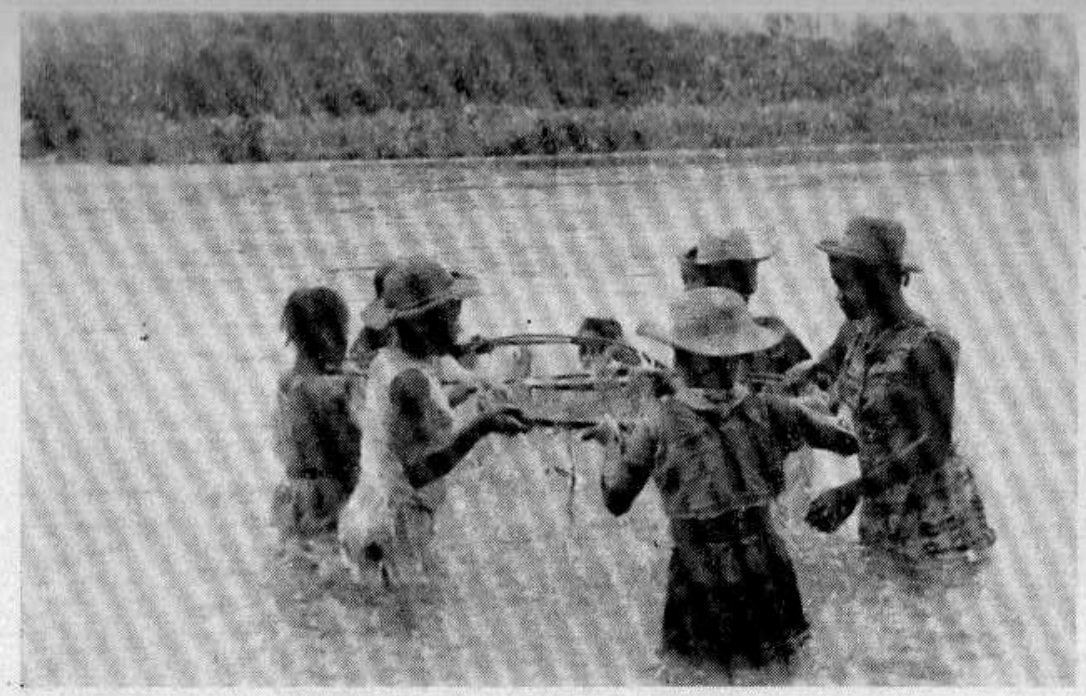

La pesca de "guañas" en el rio, reúne a las mujeres jóvenes de "Los Brazos".

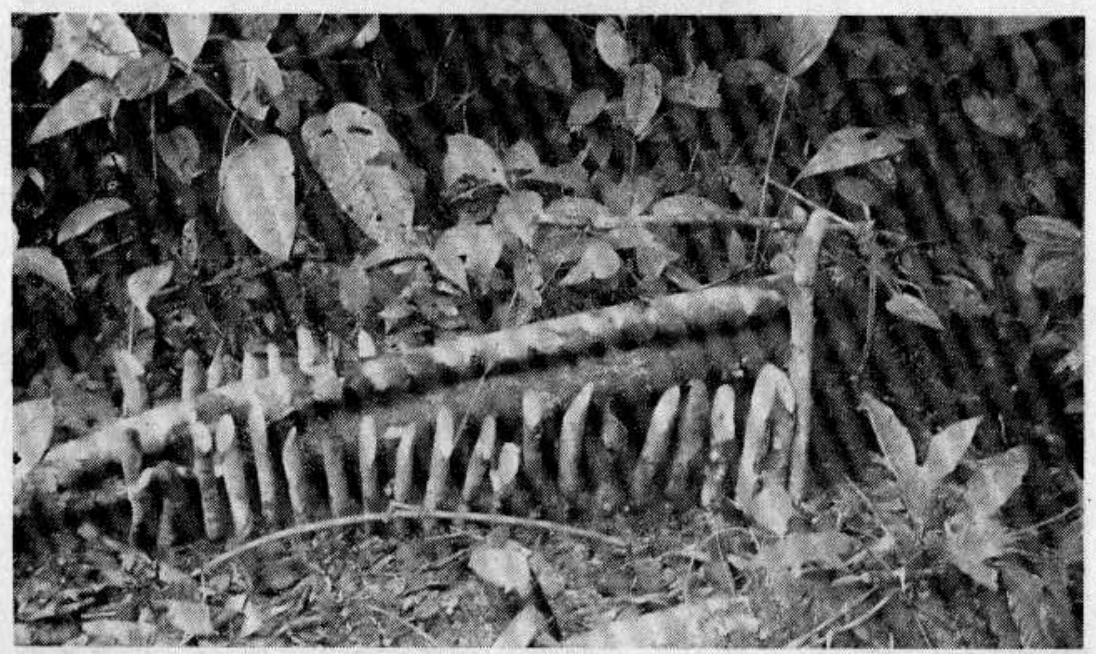

Trampa para cazar animales en el monte. 